\title{
Integration of Anhydrous Sodium Acetate (ASAc) into Concrete Pavement for Protection against Harmful Impact of Deicing Salt
}

\author{
MAZEN J. AL-KHEETAN (1) ${ }^{1,2,3}$ and MUJIB M. RAHMAN ${ }^{1,4}$ \\ 1.-Department of Civil and Environmental Engineering, College of Engineering, Design and \\ Physical Sciences, Brunel University London, Kingston Ln, Uxbridge UB8 3PH, Middlesex, UK. \\ 2.-Civil and Environmental Engineering Department, College of Engineering, Mutah University, \\ P.O. BOX 7, Mutah 61710, Karak, Jordan. 3.-e-mail: mazen.al-kheetan@brunel.ac.uk. \\ 4.-—e-mail: mujib.rahman@brunel.ac.uk
}

\begin{abstract}
Whilst application of deicing salt is essential to maintain the serviceability of concrete pavements in winter months, penetration of salt through microcracks and pores can be harmful to the underlying reinforcement. The aim of the work presented herein is to develop a shielded concrete by integrating a novel anhydrous sodium acetate (ASAc) compound into fresh concrete. The results of a comprehensive laboratory investigation to analyze the mechanical, physical, and morphological properties of the shielded concrete are presented to identify an optimum mixture design that preserves the compressive strength while enhancing the waterproofing and resistance against chloride penetration of the concrete. Trials were conducted by integrating $2 \%$ and $4 \%$ ASAc into concrete with four water-to-cement (w/c) ratios of $0.32,0.37,0.40$, and 0.46 . The initial surface absorption test, salt ponding, and compressive strength tests along with scanning electron microscopy (SEM), energy-dispersive x-ray (EDX) spectroscopy, and Fourier-transform infrared (FTIR) spectroscopy analyses were conducted to evaluate the performance and investigate the interaction mechanism of each mixture. The results demonstarted that an optimum mix design could be produced by adding $4 \%$ ASAc into mixes with w/c ratio of 0.37 or 0.32 .
\end{abstract}

\section{INTRODUCTION}

Many concrete structures are subjected to chloride attack, not only from seawater but also from deicing salts used on concrete pavements, and from the soil surrounding the pavement itself (raised marine soil). ${ }^{1}$ The easy entrance and penetration of chlorides into concrete results in numerous problems for the texture of the concrete itself as well as the steel embedded within. ${ }^{2-4}$ The deterioration process of reinforced concrete starts with penetration of water, which carries chloride ions through the pores in concrete, initiating rust in the steel, which in turn permeates into the surrounding concrete. Finally, due to rust expansion, cracks start to appear in the structure, resulting in spalling and delamination of the concrete. ${ }^{5,6}$ As a result, various maintenance and repair steps have always been followed to rehabilitate such structures and increase their service life. However, the cost of rehabilitation is sometimes greater than the construction cost of the same structure. ${ }^{7}$ Therefore, industry and research administrators have introduced some cost-effective solutions for such concrete problems that start with the construction phase. ${ }^{8,9}$

Many protective materials, such as silane and siloxane, have been used over the years to decrease the rate of deterioration caused by chloride and water ingress into concrete ${ }^{10-13}$ Silane and siloxane materials were some of the first materials to be used in this context and have shown some promising results in terms of increasing the service life of concrete. ${ }^{14-22}$ Furthermore, various other cementitious materials, pore blockers, acrylic coatings, sealers, etc. have been widely used to reduce water absorption by concrete and increase its durability. ${ }^{23-26}$ However, the use of solvent-based materials in these treatments, their improper performance when applied to wet surfaces, and their inconvenient application methods, especially for concrete 
roadways and bridges which must be closed to vehicles, have driven researchers to seek new alternate environmentally friendly materials. ${ }^{27-31}$ Accordingly, water-based materials and silicon compounds have been introduced to address the disadvantages of solvent-based materials in general and of silane/siloxane in particular. ${ }^{29,30}$

However, little research has been carried out on the internal integration of anhydrous sodium acetate (ASAc) into concrete for such protection purposes, ${ }^{32}$ and a thorough literature search did not find any technical research discussing protection against chloride ingress using such material. The primary challenges regarding addition of such material at the mixing stage are:

1. Uncontrolled hydration due to the utilization of available water by both ASAc powder and cement content, resulting in microcracks and reduction in compressive strength.

2 . The uncertainty regarding the long-term shielding performance against attack by chloride and other harmful chemicals.

The process of activating ASAc powder using the available water in fresh concrete, and the utilization of water by conventional concrete (in the absence of ASAc) are shown in Supplementary Fig. S1.

Both challenges are tackled in the research presented herein by seeking an optimum formulation of the concrete-ASAc mix design, adding ASAc admixture into the fresh concrete to increase its durability and robustness against chloride and water ingress. The main objectives of this study are:

1. To investigate the effect of ASAc admixture on the durability of concrete, when added to the fresh mix

2. To produce an optimum formulation of concrete with the optimum ASAc dose and water-tocement ratio, to achieve the maximum chloride resistance and waterproofing

3. To preserve the compressive strength of the treated concrete to produce a chloride-resistant concrete with high compressive strength

\section{EXPERIMENTAL PROCEDURES}

\section{Materials}

Four concrete mixtures with different w/c ratios of $0.32,0.37,0.40$, and 0.46 were produced, complying with British standard (BS) 1881-125. ${ }^{33}$ Anhydrous sodium acetate material with some cementitious content, which is still under testing and development, was added to all the mixes at two different ratios, viz. $2 \%$ and $4 \%$ of cement mass. In addition, a control mix, with $0 \%$ admixture, was produced for each treated mix for comparison purposes. Table I presents the mix designs adopted for the concretes used in this study. The coding and testing program for all the treated and untreated mixes are presented in Supplementary Table SI.

\section{Test Specifications and Specimens}

A total of 192 cubes with dimensions of $100 \mathrm{~mm} \times$ $100 \mathrm{~mm} \times 100 \mathrm{~mm}$ were cast: 144 for the initial surface absorption test (ISAT) protocol and 48 for the salt ponding test. Of these, 48 cubes were cast with w/c ratio of $0.32,48$ with $0.37,48$ with 0.40 , and 48 with 0.46 . Out of each set of 48,16 were treated with $0 \%, 2 \%$, and $4 \%$ ASAc each, amongst which 12 cubes were tested for water absorption after curing periods of 7 days, 14 days, and 28 days, while 4 cubes were tested for chloride penetration. After completing the ISAT, the same cubes were used to test the compressive strength of the mixes. Supplementary Fig. S2 shows the main variables investigated in this study and the testing protocol used to achieve the optimal protection performance.

The consistency of all the treated and untreated concrete samples was determined by the slump test. ${ }^{34}$ After casting, all the concrete samples in 100$\mathrm{mm}$ molds were cured for 7 days, 14 days, and 28 days in a water bath at temperature of $21^{\circ} \mathrm{C}$. Once each curing period had finished, the cubes were dried to constant mass in an oven at $105^{\circ} \mathrm{C}$. The water absorption of all the treated and untreated concrete samples was determined by using the ISAT. ${ }^{35}$

Table I. Proportions in the tested concretes

\begin{tabular}{|c|c|c|c|c|}
\hline \multirow[b]{2}{*}{ Ingredient } & \multicolumn{4}{|c|}{ Amount $\left(\mathbf{k g} / \mathbf{m}^{\mathbf{3}}\right)$} \\
\hline & $\mathrm{w} / \mathrm{c}=\mathbf{0 . 3 2}$ & $\mathrm{w} / \mathrm{c}=\mathbf{0 . 3 7}$ & $\mathrm{w} / \mathrm{c}=0.40$ & $\mathrm{w} / \mathrm{c}=0.46$ \\
\hline $\begin{array}{l}\text { Cement }(\mathrm{CEM} \mathrm{II} / 32.5 \mathrm{~N} \text {; sulfates }<3.5 \% \text {, } \\
\text { chlorides }<0.10 \% \text {, initial setting time around } 1.25 \mathrm{~h})\end{array}$ & 513 & 491 & 450 & 457 \\
\hline Water & 164 & 182 & 180 & 210 \\
\hline $\begin{array}{l}\text { Fine aggregate (sharp silica sand, uniform grain } \\
\text { size distribution between } 1 \mathrm{~mm} \text { and } 300 \mu \mathrm{m} \text { ) }\end{array}$ & 658 & 660 & 678 & 660 \\
\hline $\begin{array}{l}\text { Coarse aggregate (crushed stones with sharp edges } \\
\text { and maximum size of } 20 \mathrm{~mm} \text { ) }\end{array}$ & 1068 & 1070 & 1092 & 1073 \\
\hline
\end{tabular}


The resistance of each concrete to chloride penetration was evaluated by using the unidirectional salt-ponding test on $100-\mathrm{mm}$ cubes with a $15-\mathrm{mm}$ deep recess incorporated on their top face for 90 days. $^{36-38}$ Salt solution with $\mathrm{NaCl}$ concentration of $5 \%$ was used in the test. All four external sides of the cubes and the four internal sides of the 15-mm recess were sealed using a waterproof sealant to prevent evaporation of water from the concrete or ingress of water through any surface except the upper face. After running the test for 90 days, $2 \mathrm{~g}$ powder samples were collected by drilling the cubes at different depths of $5 \mathrm{~mm}, 10 \mathrm{~mm}, 15 \mathrm{~mm}, 20 \mathrm{~mm}$, and $50 \mathrm{~mm}$. Finally, the chloride content was evaluated by using Volhard's method following BS EN 14629. ${ }^{39}$ Supplementary Fig. S3 shows a representative sketch of the shape and size of the concrete cubes used for salt ponding testing.

The compressive strength of all the treated and untreated mixes was evaluated after 7 days, 14 days, and 28 days of curing, following the guidelines of BS EN 12390-3. ${ }^{40}$ Also, the microstructure of each material and its integration and interaction within the concrete mix were studied by scanning electron microscopy (SEM), energy-dispersive x-ray (EDX) spectroscopy, and Fourier-transform infrared (FTIR) spectroscopy. Samples were coated with a thin film of gold before SEM analysis, since both the added material and the concrete are nonconductive. Finally, the hydrophobicity of the concrete treated with ASAc was assessed by measuring the contact angle ( $\theta$ in degrees) of a sessile water drop on concrete. ${ }^{41,42}$

\section{RESULTS AND DISCUSSION}

\section{Consistency of Mixtures}

The workability of each concrete was determined by using the slump test; ${ }^{34}$ the results for all the treated and control mixes are presented in Table II. Increasing the amount of ASAc added to the concrete mix increased its consistency and flow

Table II. Slump values for all treated and control mixes

\begin{tabular}{lc}
\hline Concrete mixture & Workability $(\mathbf{m m})$ \\
\cline { 2 - 2 } $32 / 0 \mathrm{~K}$ & 0 \\
$32 / 2 \mathrm{~K}$ & 0 \\
$32 / 4 \mathrm{~K}$ & 0 \\
$37 / 0 \mathrm{~K}$ & 0 \\
$37 / 2 \mathrm{~K}$ & 5 \\
$37 / 4 \mathrm{~K}$ & 20 \\
$40 / 0 \mathrm{~K}$ & 5 \\
$40 / 2 \mathrm{~K}$ & 15 \\
$40 / 4 \mathrm{~K}$ & 70 \\
$46 / 0 \mathrm{~K}$ & 25 \\
$46 / 2 \mathrm{~K}$ & 50 \\
$46 / 4 \mathrm{~K}$ & 160 \\
\hline
\end{tabular}

properties. Despite the high slump of the $46 / 4 \mathrm{~K}$ mix, no apparent cracks were observed after aging for 7 days, 14 days, or 28 days. The $32 / 2 \mathrm{~K}$ and $32 /$ $4 \mathrm{~K}$ mixes resulted in hard concrete with zero slump. Regardless of the low slump values and the difficulty of compacting the mixes, very good compacted mixes were created with no visible cracks.

\section{Morphological Analysis}

\section{Microstructure Analysis}

EDX analysis was carried out to clarify the morphology of the ASAc material, revealing sodium, oxygen, and carbon as the main elements, with small percentages of silicon and calcium. The formation of crystals after mixing this material with concrete may correspond to the presence of sodium acetate in its composition; water activates its reaction with concrete to form crystals inside the pores. ${ }^{32}$ Also, it is believed that silicon and sodium, which were also present in this material, will react with calcium hydroxide present in the concrete, in presence of water, to form silica gel that adheres to the walls of the pores. ${ }^{43,44}$ This gel will develop into solid crystals after its hydration. The structure of crystals formed from the aforementioned reactions can be recognized in the SEM micrographs in Fig. 1a and b, where they appear as needle-shaped crystals. The formation of crystals of this shape may support easy integration of the material into the concrete mix, acting to improve its density and reduce the size of pores, making them finer. ${ }^{44,45}$ This can be seen in the interaction between the material and concrete in Fig. 1c and d, which show graphs of the cross-sectional area of the internal parts of the concrete. It is noted that the crystals are well distributed within the concrete mix, appearing with very small sizes (below $200 \mathrm{~nm}$ ), which facilitates their implantation inside capillary pores. ${ }^{30,46}$ The presence of crystals within the concrete structure in such a dense and well-distributed way would give the treated concrete rigidity and strength, as discussed below in Compressive Strength Analysis section.

After running the salt ponding test, all the concrete samples were investigated to evaluate the presence of chloride at depth of $20 \mathrm{~mm}$ (Table III). The cross-sections of all the concrete mixes revealed the presence of chloride as white spots with different densities. White spots of chloride could be found adhered to some areas of concrete with either minimum or no presence of ASAc. The micrographs at $50,000 \times$, as outlined in Table III, showed insignificant presence of chloride in the $37 / 4 \mathrm{~K}$ and $32 / 4 \mathrm{~K}$ mixes, indicating their high robustness to chloride compared with the other mixes. The presence of chloride at such low densities in those two mixes may correspond to two factors: their low w/c ratio, which contributes to reducing the size of the pore structure, ${ }^{47}$ and the presence of ASAc in proportions compatible with the w/c ratio, which 

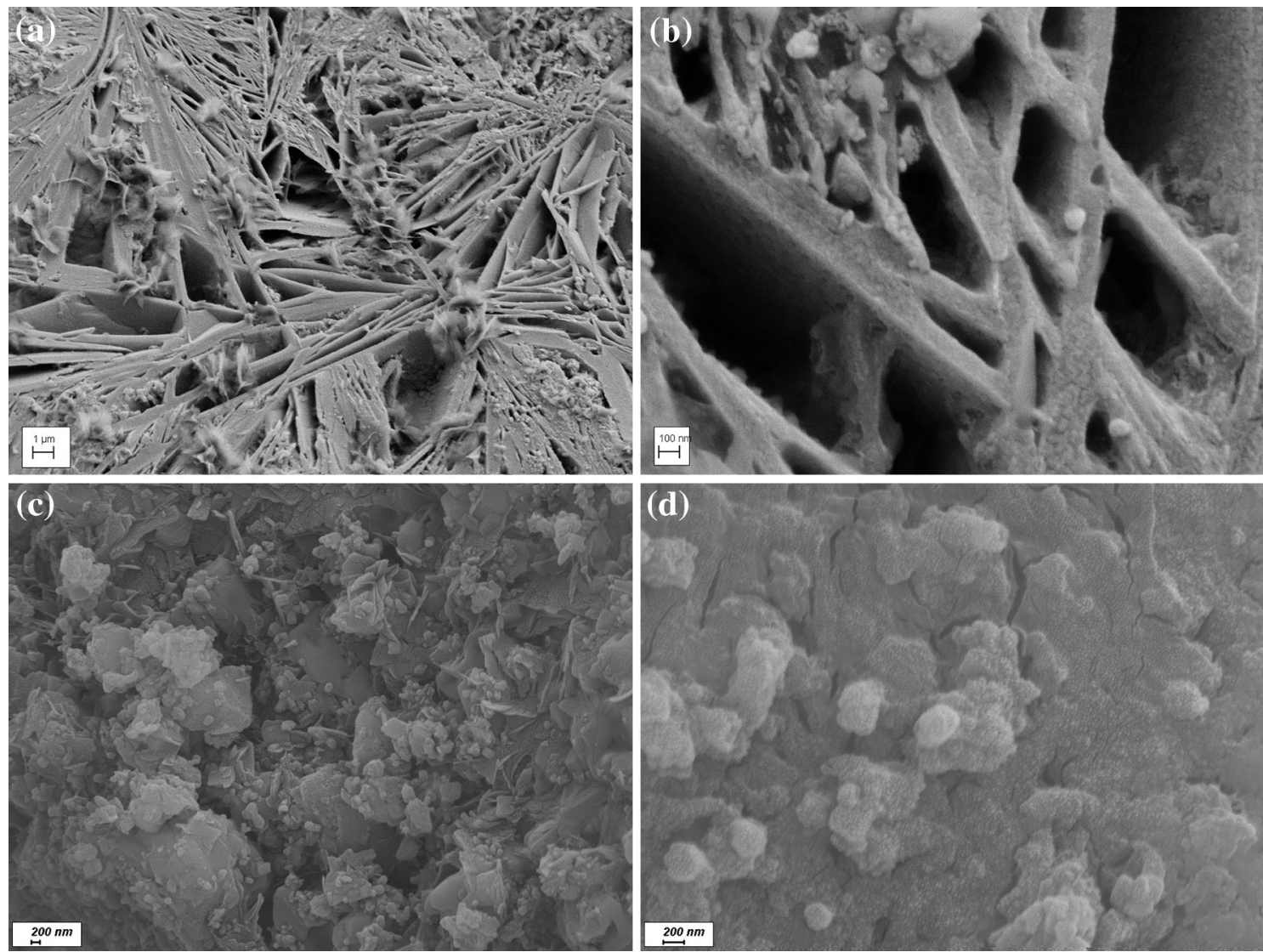

Fig. 1. SEM micrographs of (a) ASAc before mixing with concrete $(\times 10,000)$, (b) ASAc before mixing with concrete $(\times 100,000)$, (c) the interaction between ASAc and concrete $(\times 20,000)$, and (d) the interaction between ASAc and concrete $(\times 50,000)$.

does not negatively affect the hydration process. ${ }^{30}$ The first attack of chloride on concrete, when its carrier solution starts to permeate through the pores, results in combination of hydration products with chloride until a steady state between free and combined chloride is achieved. ${ }^{48}$ In the case of the mixes with low w/c ratios, this process would help to reduce the chloride penetration further, especially for additive amounts compatible with the w/c ratio, in contrast to other mixes with higher additive amounts which would hinder the hydration process and decrease the presence of hydration products that are necessary to achieve the previously mentioned stability.

\section{Functional Groups of the Protective Material}

FTIR spectra of the protective material and its interaction with concrete are shown in Fig. 2 by three spectra corresponding to the concrete powder, ASAc powder, and concrete integrated with ASAc. The characteristic peaks at $2969 \mathrm{~cm}^{-1}, 2881 \mathrm{~cm}^{-1}$, and $875 \mathrm{~cm}^{-1}$ remained almost steady and unchanged for ASAc and the concrete mixed with ASAc. Amongst these, the peak at $875 \mathrm{~cm}^{-1}$ mostly corresponds to $-\mathrm{CO}_{3}$ bond, ${ }^{49,50}$ whereas the peaks in the range from $2969 \mathrm{~cm}^{-1}$ to $2881 \mathrm{~cm}^{-1}$ are believed to correspond to $-\mathrm{CH}$ and $-\mathrm{OH}$ stretching vibrational bonds resulting from anharmonic resonances of - $\mathrm{CH}$ and $-\mathrm{OH}$ bonds in the crystal of the acetic acid chain $\left(\mathrm{CH}_{3} \mathrm{COOH}\right)$ forming sodium acetate. ${ }^{50}$ The most considerable variation in the transmittance peaks was observed at $1599 \mathrm{~cm}^{-1}, 1479 \mathrm{~cm}^{-1}, 1380 \mathrm{~cm}^{-1}$, $1320 \mathrm{~cm}^{-1}, 1116 \mathrm{~cm}^{-1}$, and $1060 \mathrm{~cm}^{-1}$. The peak at $1599 \mathrm{~cm}^{-1}$ corresponds to -COO bond, the peaks in the range from $1479 \mathrm{~cm}^{-1}$ to $1380 \mathrm{~cm}^{-1}$ may correspond to stretching vibrations of $\mathrm{C}-\mathrm{H}$ bond, ${ }^{51,52}$ and those in the range from $1060 \mathrm{~cm}^{-1}$ to $1116 \mathrm{~cm}^{-1}$ correspond to stretching vibrations of $\mathrm{C}-\mathrm{O}$ bond in the - $\mathrm{COOH}$ carboxylic acid part. Finally, the peak at $1320 \mathrm{~cm}^{-1}$ corresponds to C-O doublet bond in the same $-\mathrm{COOH}$ part. ${ }^{53,54}$

An increase in the intensity is noticed for the peaks in the ranges from $1479 \mathrm{~cm}^{-1}$ to $1380 \mathrm{~cm}^{-1}$ and $2969 \mathrm{~cm}^{-1}$ to $2881 \mathrm{~cm}^{-1}$ (C-H and $\left.\mathrm{O}-\mathrm{H}\right)$ when ASAc is mixed with concrete (Fig. 2). This increase in the hydrogen bond can be ascribed to the chemical reaction between ASAc and cement in the presence of water, where anhydrous sodium acetate dissociates in water, forming $\mathrm{CH}_{3} \mathrm{COO}^{-}$and $\mathrm{Na}^{+}$ions ${ }^{55,56}$ :

$$
\mathrm{H}_{3} \mathrm{COONa} \rightarrow \mathrm{CH}_{3} \mathrm{COO}^{-}+\mathrm{Na}^{+}
$$

It is believed that $\mathrm{CH}_{3} \mathrm{COO}^{-}$ions will form a linkage with cement through their reaction with 
Table III. Chloride residues in concrete texture at 20-mm depth after testing for chloride penetration $(\times 50,000)$

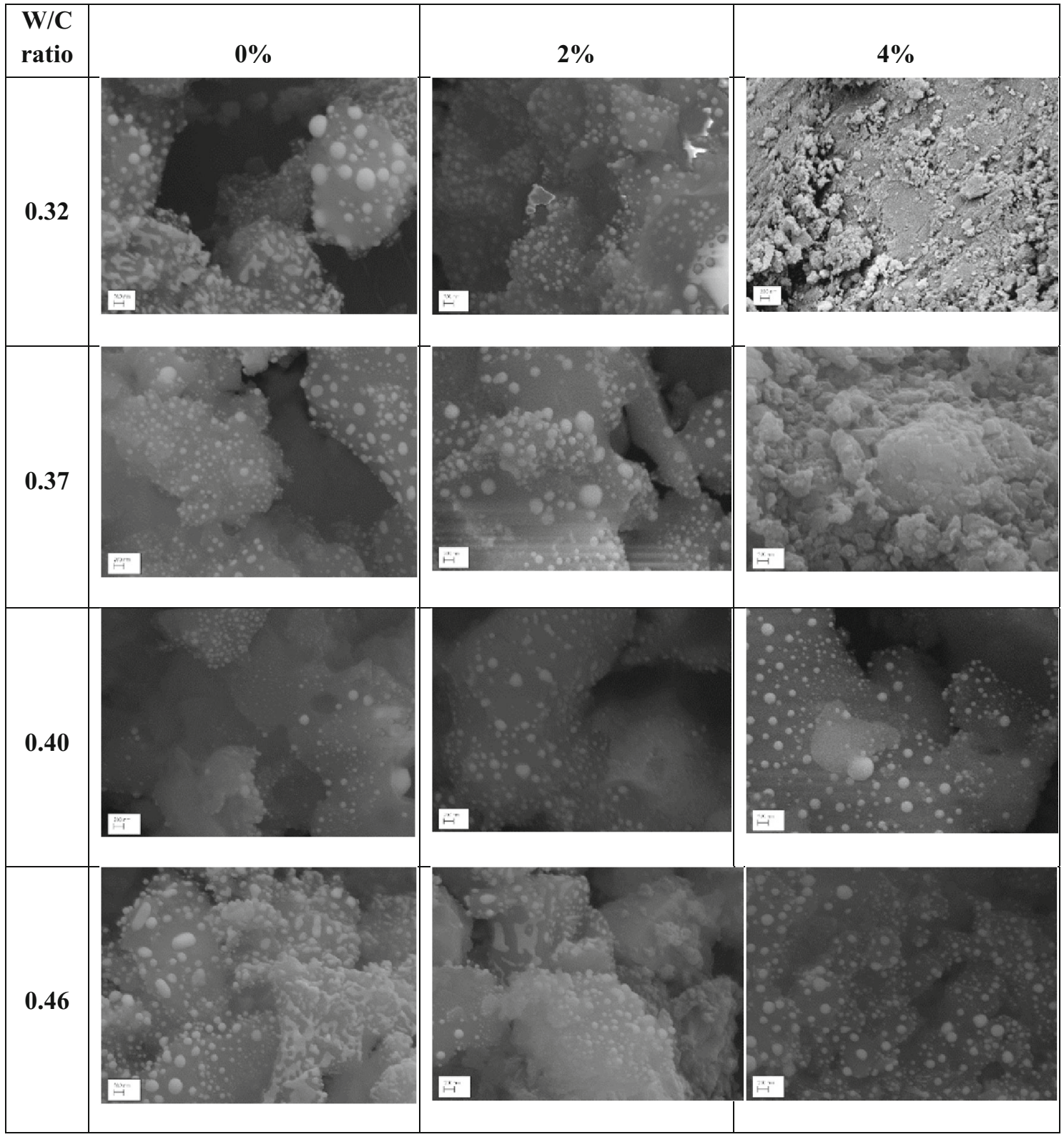

sodium already present in the cement, forming sodium acetate crystals again, which contributes to the increase in the intensity of the signals corresponding to $\mathrm{C}-\mathrm{H}$ bonds (Fig. 2). In turn, the dissociated $\mathrm{Na}^{+}$ions will react with free water, forming sodium hydroxide $(\mathrm{NaOH})$ composite, which increases the intensity of the signal corresponding to $\mathrm{O}-\mathrm{H}$ bonds. Moreover, some of the free $\mathrm{CH}_{3} \mathrm{COO}^{-}$ may react with water to form acetic acid $\left(\mathrm{CH}_{3} \mathrm{COOH}\right)$, which will also contribute to increasing the intensity of the signal corresponding to $\mathrm{O}-\mathrm{H}$ bonds. On the other hand, the reduction in the intensity of the signals corresponding to the C-O $\left(1320 \mathrm{~cm}^{-1}\right)$ and $-\mathrm{COO}\left(1599 \mathrm{~cm}^{-1}\right)$ could indicate the ionic reaction between $\mathrm{CH}_{3} \mathrm{CO}^{-}$and $\mathrm{H}^{+}$ions, forming small amounts of volatile $\mathrm{CH}_{4}$ and $\mathrm{CO}_{2} \cdot{ }^{57,58}$

The presence of small quantities of acetic acid in the mix may act to delay the hydration process and increase the workability of the concrete mixes, especially if a large amount of sodium acetate admixture is added to the mix. ${ }^{59}$ In addition, the presence of sodium hydroxide $(\mathrm{NaOH})$ in the 


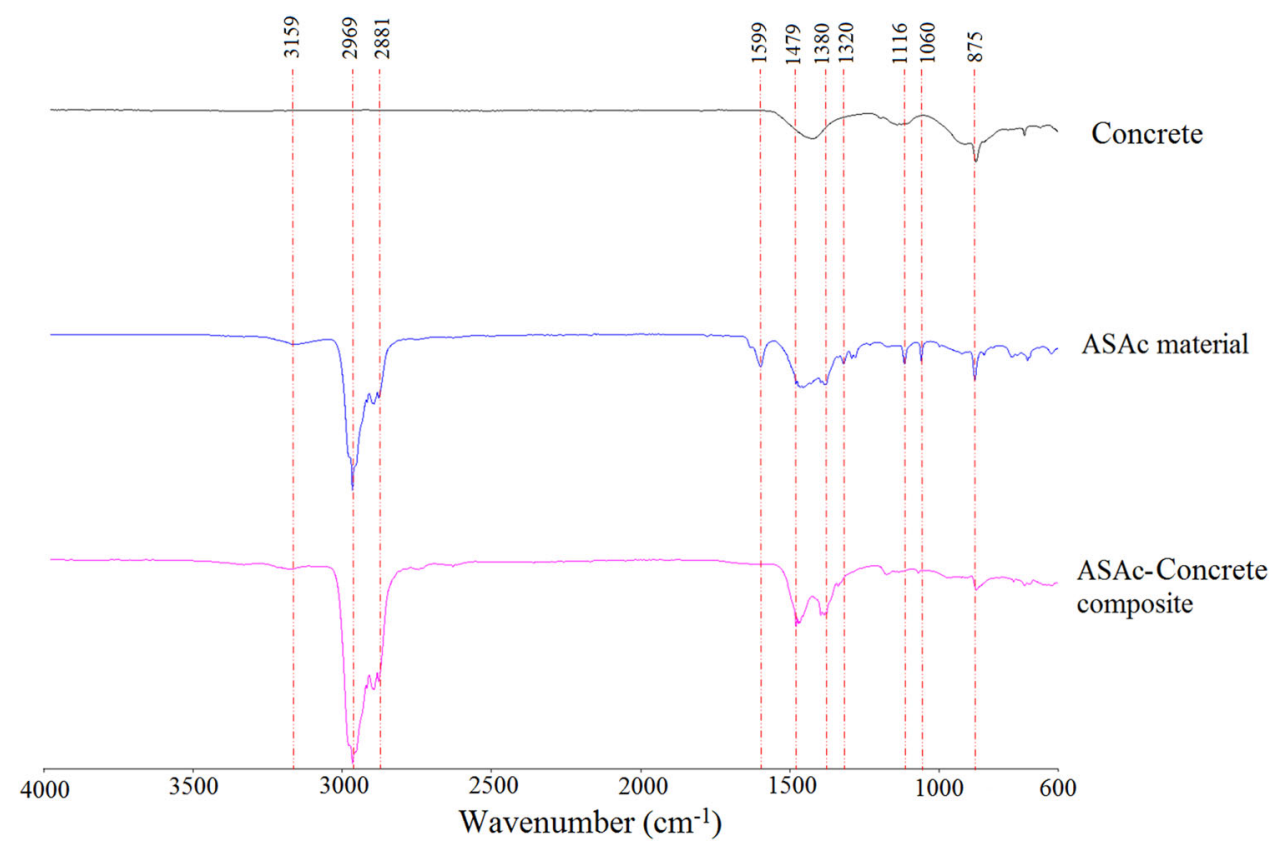

Fig. 2. FTIR analysis of concrete-ASAc composite reaction.

concrete mixes at reasonable amounts may further increase its workability, reduce the segregation, and accelerate $\mathrm{C}_{3} \mathrm{~S}$ hydration. However, large amounts of $\mathrm{NaOH}$ may contribute to decreasing the final strength of the concrete, as a result of the formation of metastable C-S-H with reduced bonding strength. ${ }^{60,61}$ Another reason for the increase in C$\mathrm{H}$ bonds is believed to be the replacement of $-\mathrm{OH}$ groups by $-\mathrm{CH}_{3}$ groups, which in turn bond with silicon atoms in the cement, resulting in the formation of a hydrophobic component integrated within the mix (organosilicon bonds). ${ }^{62-67}$ This could result in improving the hydrophobicity of the concrete treated with ASAc (Supplementary Fig. S4). Notwithstanding the modest contact angle resulting from the treatment, a clear increase in hydrophobicity resulted from integrating ASAc into the mix, especially for the $32 / 4 \mathrm{~K}$ mix, where the contact angle almost doubled compared with control. Meanwhile, some of the mixes, especially those with high $\mathrm{w} / \mathrm{c}$ ratio, suffered from a reduction in hydrophobicity, which could be due to their relatively high water content. Excess water may contribute to decreasing the organosilicon bonds that are responsible for the modest hydrophobicity of the ASAc-concrete composite.

\section{Water Absorption}

The efficacy of ASAc for reducing the water absorption by concrete was evaluated by the ISAT method. The results from the ISAT after 7 days, 14 days, and 28 days of curing are shown in Fig. 3a, $\mathrm{b}$ and $\mathrm{c}$. These graphs show the accumulative water absorption rate of all the treated and untreated samples after testing for periods from $10 \mathrm{~min}$ to $60 \mathrm{~min}$.
At 7 days, the mix with a w/c ratio of 0.32 achieved the lowest water absorption rate among all the mixes, when treated with either $2 \%$ or $4 \%$ admixture (Fig. 3a). The same performance was observed after aging for 14 days, where the mix with a $0.32 \mathrm{w} / \mathrm{c}$ ratio and treated with $4 \%$ admixture absorbed the least amount of water (Fig. 3b). After 28 days of curing, the $32 / 4 \mathrm{~K}$ and $37 / 4 \mathrm{~K}$ mixes exhibited the best performance among all the mixes, showing water absorption close to zero with efficacy of more than $50 \%$ and $60 \%$, respectively, compared with their control (Fig. 3c).

Increasing the w/c ratio of the mix above 0.37 was seen to have a negative effect on the performance of the treated concrete. Treating mixes with high w/c ratio ( 0.40 and 0.46$)$ was shown to have a negative effect after aging for 7 days, as recognized by their high water absorption rate exceeding that of the corresponding control (Fig. 3a). On increasing the curing age to 14 days, the $40 / 4 \mathrm{~K}$ and $46 / 2 \mathrm{~K}$ mixes performed better than their control. After aging for 28 days, the $40 / 2 \mathrm{~K}$ and $46 / 2 \mathrm{~K}$ mixes showed the best performance among all the mixes with w/c ratio of 0.40 or 0.46 , whereas the same mixes treated with $4 \%$ ASAc exhibited worse performance than control.

The negative effect of adding $4 \%$ admixture into the mixes with w/c ratio of 0.46 or 0.40 resulted from the higher amount of water used in these mixes, compared with the concretes with w/c ratios of 0.32 and 0.37. Adding 4\% ASAc to the concretes with relatively high w/c ratios contributed to increasing the slump value and the consistency of these mixes due to the formation of large amounts of $\mathrm{NaOH}$ (Table II), which in turn participated in the increasing air voids and microcracks. ${ }^{59}$ Another reason for this negative effect is that the interaction between 

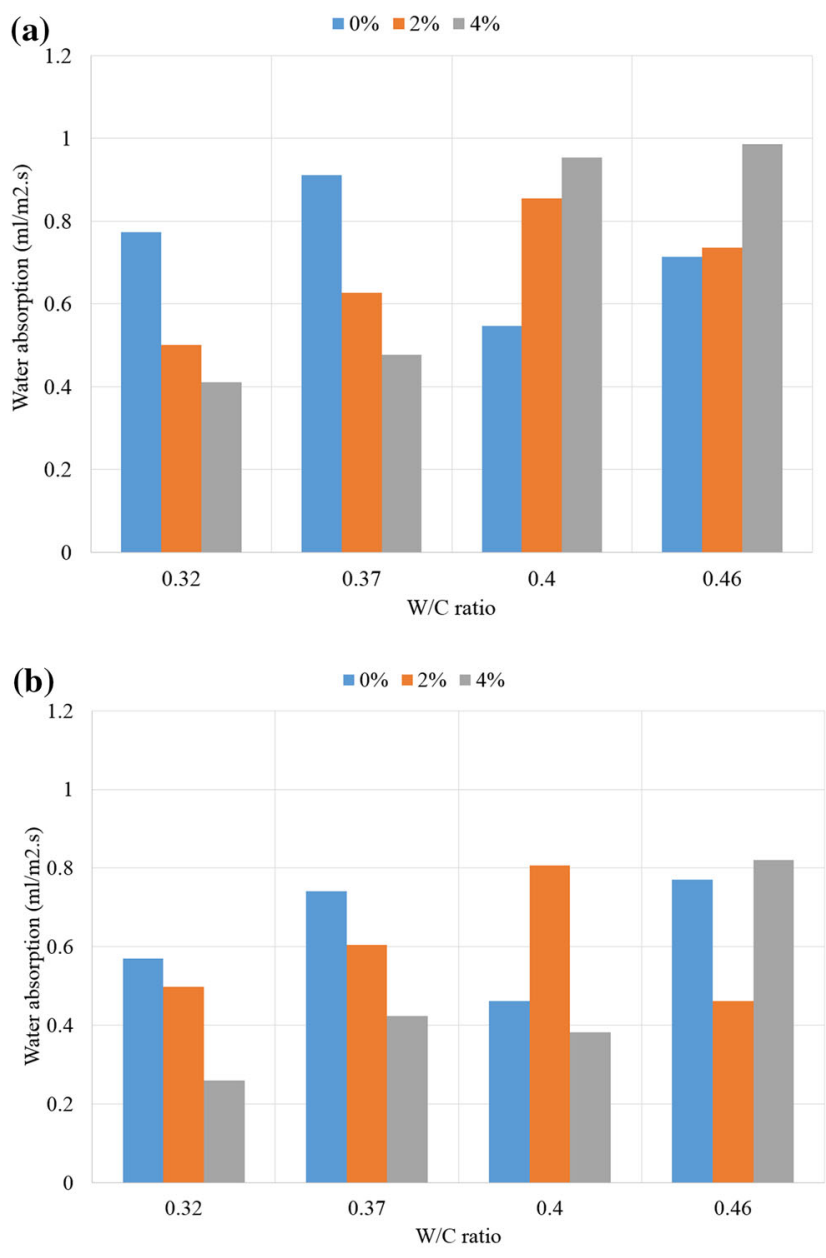

(c)

$\because 0 \% \backsim 2 \% \backsim 4 \%$

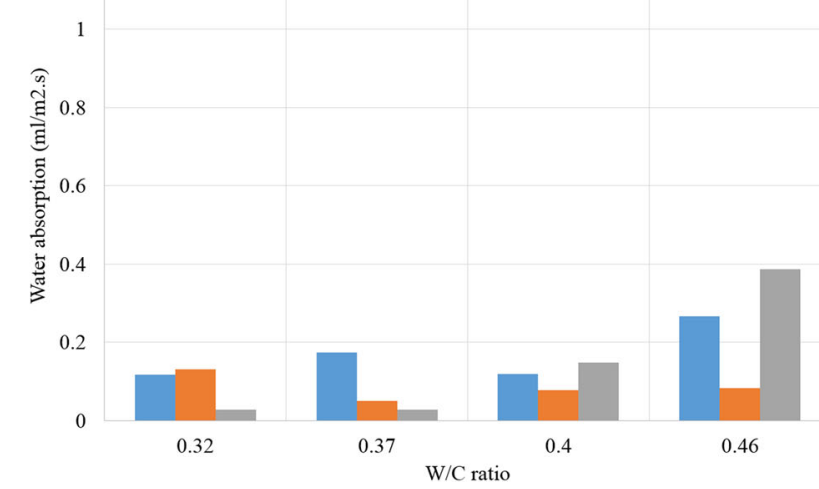

Fig. 3. Water absorption rates for all treated and untreated concrete mixes after aging for (a) 7 days, (b) 14 days, and (c) 28 days.

ASAc and cement in the presence of water will most probably contribute to the formation of a hydrophobic organosilicon-based composite (as suggested in Functional Groups of the Protective Material) section. Increasing the amount of water added to the mix with a high dose of ASAc will increase the rate of formation of the hydrophobic content. Formation of large quantities of this hydrophobic content, at early aging times, will contribute to exclusion of excess water from the pores in the concrete, decreasing the quantity of water required to progress the hydration process, which leads to the formation of some microcracks within the structure of the concrete. ${ }^{29,30}$ As a result, more water will be absorbed into the concrete, at later aging times, for the w/c ratios of 0.40 and 0.46 and treated with $4 \%$ admixture. In contrast, the concretes with w/c ratio of 0.32 or 0.37 treated with $4 \%$ admixture, or even $2 \%$ admixture, showed very high ability to combat water absorption. This could result from the use of a compatible amount of water and admixture, with no excess water present in the mix, and an amount of water suitable to initiate the reaction between ASAc and cement, and at the same time to continue the hydration process.

\section{Concrete Resistance to Chloride Penetration}

Figure 4 shows the results of testing the chloride diffusion through the treated and untreated concretes with different $\mathrm{w} / \mathrm{c}$ ratios. The chloride content was calculated based on the equation ${ }^{39}$

$$
\mathrm{CC}=3.545 * f *(V 2-V 1) / m
$$

where CC is the chloride content (\%), $f$ is the molarity of the silver nitrate solution, $V_{1}$ is the volume of ammonium thiocyanate solution used in the titration $(\mathrm{ml}), V_{2}$ is the volume of ammonium thiocyanate solution used in the blank titration $(\mathrm{ml})$, and $m$ is the mass of the concrete sample $(\mathrm{g})$.

The results of the unidirectional chloride ponding test show a general reduction in chloride content with increasing depth. The $37 / 4 \mathrm{~K}$ concrete (Fig. 4b) showed the most reduced chloride diffusion among all the mixes through the depth from $10 \mathrm{~mm}$ to $50 \mathrm{~mm}$; the chloride content at depths of $20 \mathrm{~mm}$ to $50 \mathrm{~mm}$ was reduced by more than $90 \%$ with respect to the control mix. The 32/4 K mix (Fig. 4a) showed high resistance to chloride diffusion, albeit less than that of the 37/4 K mix (Fig. 4b), with efficacy above $70 \%$ in the depth range from $20 \mathrm{~mm}$ to $50 \mathrm{~mm}$. On the other hand, adding $4 \%$ of admixture to the concrete with w/c ratio of 0.46 (46/4 K) (Fig. 4d) negatively affected the performance, resulting in an increase of the chloride absorption compared with control (7\% increase in the depth range from $20 \mathrm{~mm}$ to $50 \mathrm{~mm}$ ). The poor performance of the $46 / 4 \mathrm{~K} \mathrm{mix}$ also correlates with the high workability of the mix, as discussed in Water Absorption section. Increasing the w/c ratio contributed to increasing the voids and the size of the pore structure of the concrete, which in turn increased the rate of capillary suction and permeation through the pores. ${ }^{48}$ In addition, at the beginning of chloride transport from the surface into the concrete, chloride from the saline solution will be amalgamated by the hydration products until a balanced state between free and combined chloride is achieved. This should contribute to decreasing the concentration of chloride with increasing depth. ${ }^{48}$ However, in the case of the 

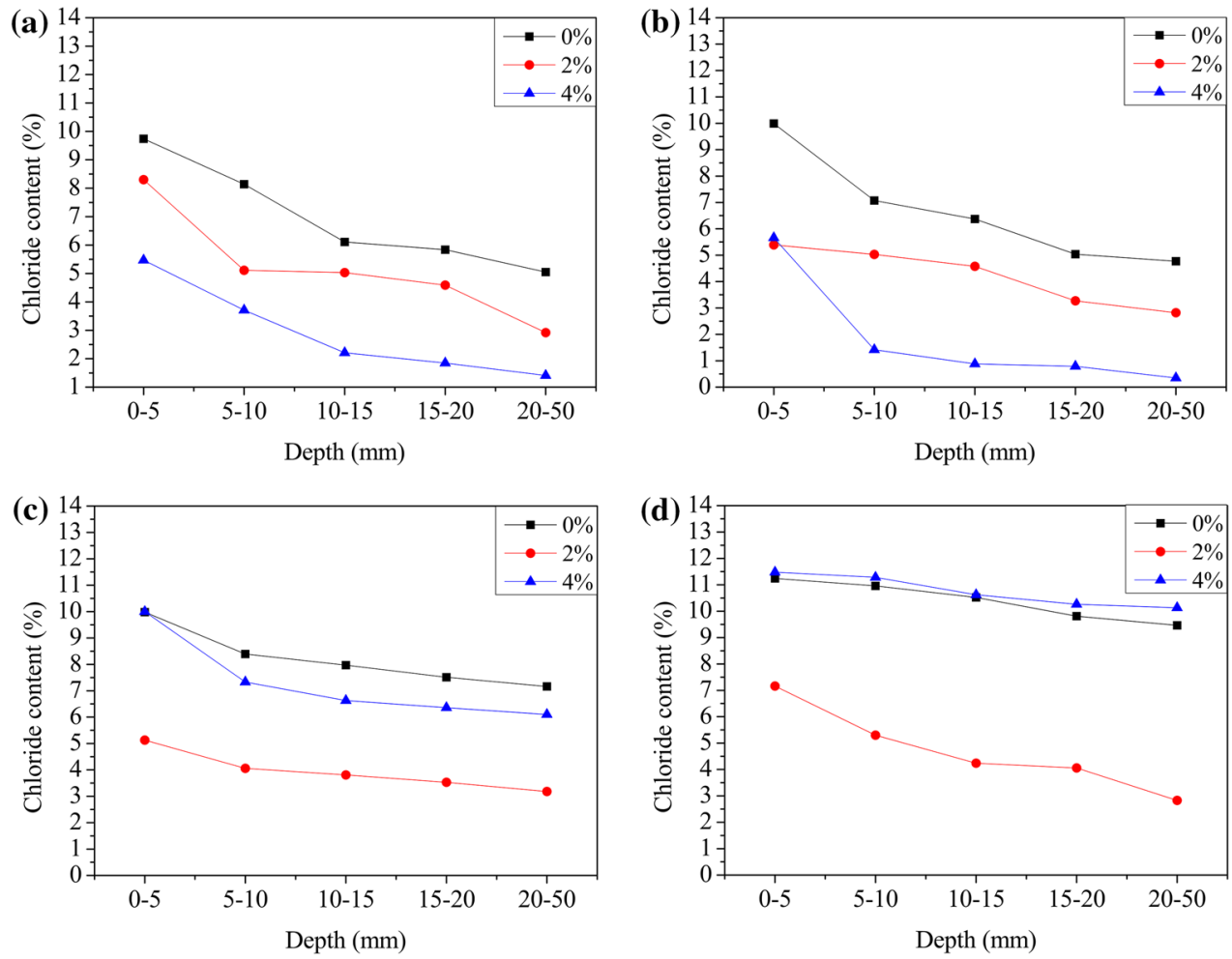

Fig. 4. Chloride content through treated and untreated concrete mixes with w/c ratio of (a) 0.32 , (b) 0.37 , (c) 0.40 , and (d) 0.46 .

mixes with high w/c ratio and high amount of additive, the additive will reduce the hydration process, preventing such a balanced condition between free and combined chloride from being reached. Moreover, the resistance of concrete to chloride diffusion followed a similar trend to that observed for the water absorption, where long-term testing revealed that it is possible to produce durable concrete when low w/c ratios are used along with the ASAc material.

\section{Compressive Strength Analysis}

After 7 days, 14 days, and 28 days of curing, the compressive strength of all the treated and control mixes was determined. The results of this test are shown in Fig. 5. A remarkable negative effect of adding the admixture to all the concrete mixes was noticed at the early aging durations of 7 days and 14 days (Fig. 5a and b). After aging for 7 days, the strength of all the mixes dropped by $3-36 \%$ with repsect to their control mix, the lowest drop being noticed for $32 / 4 \mathrm{~K}$ and the highest for $46 / 4 \mathrm{~K}$. Further strength reduction was observed for all the treated mixes after aging for 14 days compared with their control; a drop of 16-38\% in strength was noticed, with $32 / 2 \mathrm{~K}$ being the lowest and $46 / 4 \mathrm{~K}$ the highest. However, after aging for 28 days (Fig. 5c), the treatment increased the compressive strength of the mixes with w/c ratio of 0.32 or 0.37 , ranging from $13 \%$ to $42 \%$, with the maximum strength gain seen for the $37 / 4 \mathrm{~K}$ mix. On the other hand, mixes with w/c ratio of 0.40 or 0.46 treated with either $2 \%$ or $4 \%$ admixture continued to lose strength, reaching $32 \%$ in the case of $46 / 4 \mathrm{~K}$.

A negative effect of adding the admixture to all the concrete mixes was noticed after shorter aging periods of 7 days and 14 days (Fig. 5a and b). After aging for 7 days, the strength of all the mixes dropped by $3-36 \%$ with respect to their control mix, the least drop being noticed for $32 / 4 \mathrm{~K}$ and the greatest for $46 / 4 \mathrm{~K}$. Further reduction in strength was seen for all the treated mixes after aging for 14 days compared with their control; a drop of 16 $38 \%$ in strength was noticed, with $32 / 2 \mathrm{~K}$ being the lowest and $46 / 4 \mathrm{~K}$ the highest. However, after aging for 28 days (Fig. 5c), treatment increased the compressive strength of the mixes with w/c ratio of 0.32 or 0.37 , ranging from $13 \%$ to $42 \%$, with the maximum strength gain seen for the $37 / 4 \mathrm{~K}$ mix. On the other hand, the mixes with w/c ratio of 0.40 or 0.46 treated with either $2 \%$ or $4 \%$ admixture continued to lose strength, reaching $32 \%$ in the case of $46 / 4 \mathrm{~K}$.

The strength reduction seen after aging for 7 days and 14 days may correspond to the large amount of water present at that time, especially in the case of the mixes with w/c ratio of 0.40 or 0.46 . Adding the admixture to the concrete contributed to increasing the consistency of these mixes, as seen in Table II. This increased level of workability along with the 

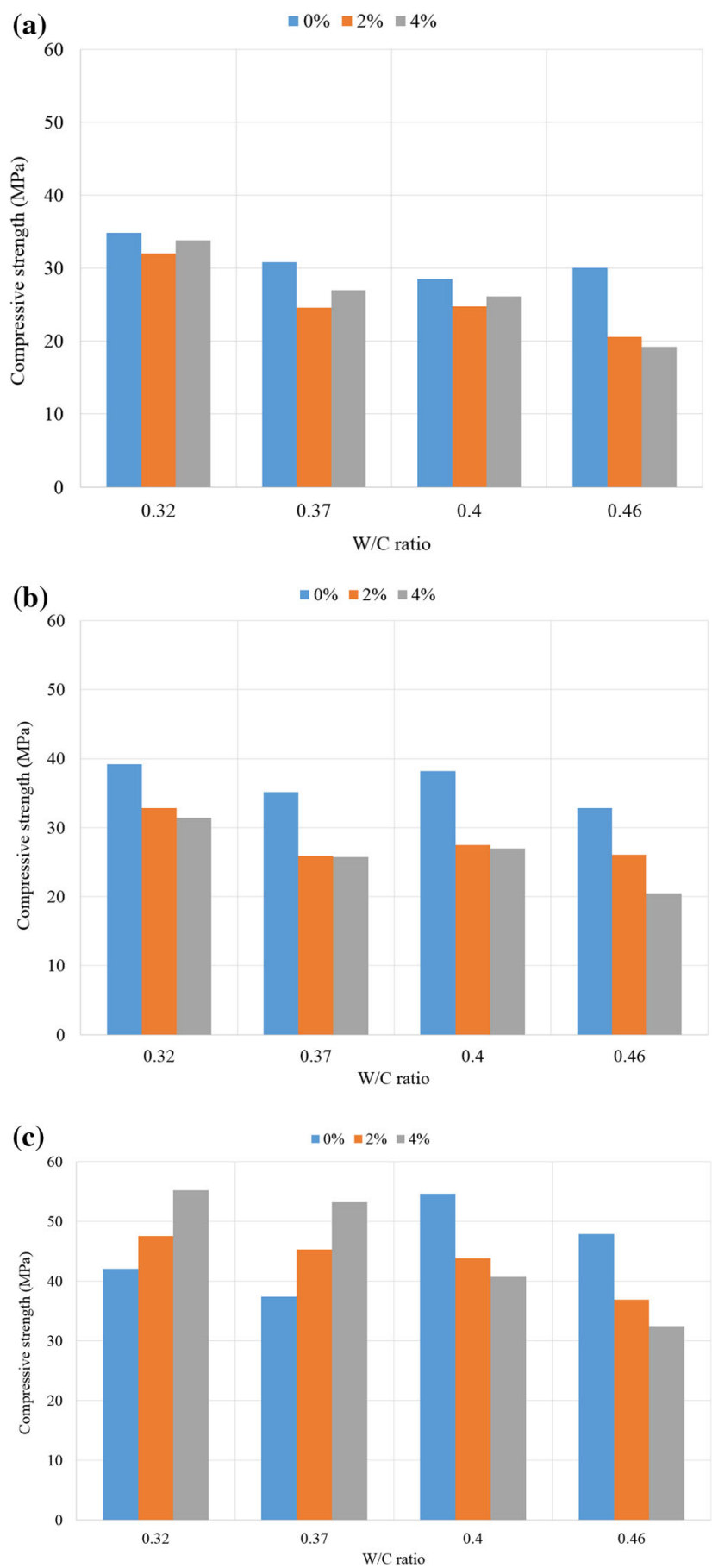

Fig. 5. Compressive strength of all treated and untreated concrete mixes after aging for (a) 7 days, (b) 14 days, and (c) 28 days.

presence of activated hydrophobic crystals may combine to delay the hydration process, resulting in the reduction in the compressive strength at these early aging times. Furthermore, after aging for 28 days, the mixes with relatively low w/c ratios managed to complete the hydration process and achieve higher compressive strength than their corresponding control. These results, when combined with the ISAT results, prove that ASAc participated in forming a denser concrete structure (refer to Morphological Analysis section) with minimum cracks or microcracks, resulting in higher compressive strength than control (in the case of the mixes with w/c ratio of 0.32 or 0.37 ). Moreover, concrete with high w/c ratio sustained its strength loss after aging for 28 days, since the hydration process was inhibited by the dual effect of adding the admixture and increasing the w/c ratio.

\section{CONCLUSION}

Twelve different concrete mixes were produced by integrating two different doses, $2 \%$ and $4 \%$, of anhydrous sodium acetate compound into mixes with four different w/c ratios of $0.32,0.37,0.40$ and 0.46 , in order to identify an ideal mix with reduced water absorption and chloride diffusion while preserving the compressive strength of the primary mix. The conclusions of this research can be summarized as follows:

1. Adding the ASAc material to the fresh mix contributed to increasing the workability of the mixes with high w/c ratios, with complete slump being observed in the case of the $46 / 4 \mathrm{~K}$ mix.

2. A significant reduction in water absorption was witnessed in the case of the $32 / 4 \mathrm{~K}$ and $37 / 4 \mathrm{~K}$ mixes after all the aging periods of 7 days, 14 days, and 28 days, with a maximum impermeability rate of $64 \%$ for $37 / 4 \mathrm{~K}$ after aging for 28 days.

3. Chloride diffusion was reduced by more than $90 \%$ in the depth range from $20 \mathrm{~mm}$ to $50 \mathrm{~mm}$ in the case of the $37 / 4 \mathrm{~K} \mathrm{mix}$, and by more than $70 \%$ in the depth range from $20 \mathrm{~mm}$ to $50 \mathrm{~mm}$ in the case of the $32 / 4 \mathrm{~K}$ mix.

4. An increase in the compressive strength after aging for 28 days was noticed when adding a dose of $2 \%$ or $4 \%$ to mixes with w/c ratio of 0.32 or 0.37 . The maximum strength gain of $42 \%$ was observed in the case of the $37 / 4 \mathrm{~K} \mathrm{mix}$, and the minimum of $13 \%$ for the $32 / 2 \mathrm{~K}$ mix.

5. Mixes with high w/c ratio suffered from strength loss after all the aging periods, with a significant strength reduction of $32 \%$ for the $46 / 4 \mathrm{~K}$ mix after aging for 28 days.

6. An optimum mix could be design by adding $4 \%$ of the ASAc material to a mix with w/c ratio of 0.37 . The next optimal mix would be prepared by adding $4 \%$ of ASAc material to the concrete with $0.32 \mathrm{w} / \mathrm{c}$ ratio.

\section{ACKNOWLEDGEMENT}

The authors would like to acknowledge the help and support provided by the Experimental Technique Centre (ETC) at Brunel University London, and its researchers Dr. Nico Nelson, Dr. Lorna Anguilano, Dr. Safiyeh Haghani, and Dr. Ashley Howkins. 


\section{CONFLICT OF INTEREST}

The author declares that they have no conflict of interest.

\section{OPEN ACCESS}

This article is distributed under the terms of the Creative Commons Attribution 4.0 International License (http://creativecommons.org/licenses/by/4.0/ ), which permits unrestricted use, distribution, and reproduction in any medium, provided you give appropriate credit to the original author(s) and the source, provide a link to the Creative Commons license, and indicate if changes were made.

\section{ELECTRONIC SUPPLEMENTARY MATERIAL}

The online version of this article (https://doi.org/ 10.1007/s11837-019-03624-3) contains supplementary material, which is available to authorized users.

\section{REFERENCES}

1. E. Poulsen and L. Mejlbro, Diffusion of Chloride in Concrete: Theory and Application (Cambridge: CRC Press, 2014).

2. J. Dai, Y. Akira, F. Wittmann, H. Yokota, and P. Zhang, Cement Concr. Compos. 32, 101 (2010).

3. J. Liu, Q. Qiu, X. Chen, F. Xing, N. Han, Y. He, and Y. Ma, Cement Concr. Res. 95, 217 (2017).

4. K.D. Baldie and P. Pratt, MRS Online Proceedings Library Archive, Vol. 64 (1985).

5. A. Suwito and Y. Xi, Life-Cycle Performance of Deteriorating Structures: Assessment, Design and Management, ed. D.M. Frangopol, E. Bruohwiler, M.H. Faber, and B. Adey (Lausanne, Switzerland: ASCE Press, 2004), p. 207.

6. A.G. Constantinou and K.L. Scrivener, MRS Online Proceedings Library Archive, Vol. 370 (1994).

7. M. Ibrahim, A. Al-Gahtani, M. Maslehuddin, and A. Almusallam, Constr. Build. Mater. 11, 443 (1997).

8. E. Franzoni, B. Pigino, and C. Pistolesi, Cement Concr. Compos. 44, 69 (2013).

9. K.L. Scrivener and R.J. Kirkpatrick, Cement Concr. Res. 38, 128 (2008).

10. L. Bertolini, B. Elsener, P. Pedeferri, E. Redaelli, and R.B. Polder, Corrosion of Steel in Concrete: Prevention, Diagnosis, Repair (New York: Wiley, 2013).

11. C. Dry, Cement Concr. Res. 30, 1969 (2000).

12. Z. Lu and X. Zhou, Cement Concr. Res. 30, 227 (2000).

13. A. Brenna, F. Bolzoni, S. Beretta, and M. Ormellese, Constr. Build. Mater. 48, 734 (2013).

14. J. De Vries and R. Polder, Constr. Build. Mater. 11, 259 (1997).

15. P. Basheer, L. Basheer, D. Cleland, and A. Long, Constr. Build. Mater. 11, 413 (1997).

16. C. Christodoulou, H. Tiplady, C. Goodier, and S. Austin, Concrete Solutions 2014, Proceedings of Concrete Solutions, the 5th International Conference on Concrete Repair, 1-3 September, Belfast, ed. M. Grantham, et al. (Boca Raton, FL: CRC Press, 2014), pp. 385-392.

17. H. Herb, A. Gerdes, and G. Brenner-Weiß, Cement Concr. Res. 70, 77 (2015).
18. F. Tittarelli and G. Moriconi, Cement Concr. Res. 38, 1354 (2008).

19. I. Flores-Vivian, V. Hejazi, M.I. Kozhukhova, M. Nosonovsky, and K. Sobolev, ACS Appl. Mater. Interfaces. 5, 13284 (2013).

20. A. Stewart, B. Schlosser, and E.P. Douglas, ACS Appl. Mater. Interfaces. 5, 1218 (2013).

21. B. Pang, Y. Zhang, G. Liu, and W. She, ACS Appl. Mater. Interfaces. 10, 21696 (2018).

22. M.J. Al-Kheetan, M. Rahman, B.N. Muniswamappa, and D. Chamberlain, Can. J. Civ. Eng. (2019). https://doi.org/10.1 139/cjce-2018-0546.

23. M.J. Al-Kheetan, M.M. Rahman, and D.A. Chamberlain, Constr. Build. Mater. 141, 64 (2017).

24. M.K. Moradllo, M. Shekarchi, and M. Hoseini, Constr. Build. Mater. 30, 198 (2012).

25. R.N. Swamy, A.K. Suryavanshi, and S. Tanikawa, Mater. J. 95, 101 (1998).

26. American Concrete Institute, Committee 515, Farmington Hills, MI (2013).

27. M.J. Al-Kheetan, M.M. Rahman, and D.A. Chamberlain, Int. J. Pavement Eng. (2019). https://doi.org/10.1080/10298 436.2019.1567917.

28. M.C. Bubalo, K. Radošević, I.R. Redovniković, J. Halambek, and V.G. Srček, Ecotoxicol. Environ. Saf. 99, 1 (2014).

29. M.J. Al-Kheetan, M.M. Rahman, and D.A. Chamberlain, Constr. Build. Mater. 160, 644 (2018).

30. M.J. Al-Kheetan, M.M. Rahman, and D.A. Chamberlain, Struct. Concr. 19, 1504 (2018).

31. M.J. Al-Kheetan, M.M. Rahman, and D.A. Chamberlain, Int. J. Build. Pathol. Adapt. 36, 77 (2018).

32. A. Al-Otoom, A. Al-Khlaifa, and A. Shawaqfeh, Ind. Eng. Chem. Res. 46, 5463 (2007).

33. British Standards Institution, BS 1881-125, British Standard Institution, London (2013).

34. British Standards Institution, BS EN 12350-2, British Standard Institution, London (2009).

35. British Standards Institution, BS EN 1881-208, British Standard Institution, London (1996).

36. American Association of State Highway and Transportation Officials, Resistance of Concrete to Chloride Ion Penetration (Washington, DC: American Association of State Highway and Transportation Officials (AASHTO), 2002).

37. M. Rahman and D. Chamberlain, J. Mater. Civ. Eng. 29, 04017008 (2017).

38. M. Rahman, D. Chamberlain, M. Balakhrishna, and J. Kipling, Transp. Res. Rec. J. Transp. Res. Board 2342, 17 (2013).

39. British Standards Institution, BS EN 14629, British Standard Institution, London (2007).

40. British Standards Institution, BS EN 12390-3, British Standard Institution, London (2009).

41. A.M. Anderson and M.K. Carroll, Aerogels Handbook, ed. N. Leventis and M.M. Koebel (Berlin: Springer, 2011), p. 47.

42. D. Li and A. Neumann, J. Colloid Interface Sci. 148, 190 (1992).

43. V.G. Cappellesso, N. dos SantosPetry, D.C.C. Dal Molin, and A.B. Masuero, J. Build. Pathol. Rehabilit. 1, 9 (2016).

44. L. Teng, R. Huang, J. Chen, A. Cheng, and H. Hsu, Materials 7, 399 (2014).

45. M. Kumar, N. Singh, and N. Singh, Indian J. Chem. Technol. 16, 499 (2009)

46. S. Chen, R. Huang, H. Hsu, S. Zou, and L. Teng, J. Mar. Sci. Technol. 24, 244 (2016).

47. A. Costa and J. Appleton, Mater. Struct. 32, 252 (1999).

48. H. Hilsdorf and J. Kropp, Performance Criteria for Concrete Durability (Boca Roton: CRC Press, 2014).

49. C. Rey, V. Renugopalakrishman, B. Collins, and M.J. Glimcher, Calcif. Tissue Int. 49, 251 (1991).

50. M. Gadermann, D. Vollmar, and R. Signorell, Phys. Chem. Chem. Phys. 9, 4535 (2007).

51. C. Iacovita, R. Stiufiuc, T. Radu, A. Florea, G. Stiufiuc, A. Dutu, S. Mican, R. Tetean, and C.M. Lucaciu, Nanoscale Res. Lett. 10, 391 (2015). 
52. M. Ibrahim, A. Nada, and D.E. Kamal, Indian J. Pure Appl. Phys. 43, 911 (2005)

53. R.M. Silverstein, F.X. Webster, D.J. Kiemle, and D.L. Bryce, Spectrometric Identification of Organic Compounds (New York: Wiley, 2014).

54. National Institute of Standers and Technology, "U.S. Department of Commerce", https://webbook.nist.gov/chemis try/vib-ser/. Accessed 12 April 2018.

55. R. Chang, Physical Chemistry for the Biosciences (Sausalito: University Science Books, 2005).

56. B. Sharma, Objective Question Bank in Chemistry (Meerut: Krishna Prakashan Media, 1997).

57. F. Woodard, Industrial Waste Treatment Handbook (Boston: Butterworth Heinemann, 2001).

58. J.G. Ferry, J. Bacteriol. 174, 5489 (1992).

59. D.D. Nguyen, L.P. Devlin, P. Koshy, and C.C. Sorrell, J. Therm. Anal. Calorim. 123, 489 (2016).

60. V.S. Ramachandran, Concrete Admixtures Handbook: Properties, Science and Technology (Norwich: William Andrew, 1996).
61. F. Collins and J. Sanjayan, Cement Concr. Res. 29, 455 (1999).

62. L.E.M. Palomino, Z. Pászti, I.V. Aoki, and H.G.D. Melo, Mater. Res. 10, 399 (2007).

63. P. Wagh, S. Ingale, and S.C. Gupta, J. Sol Gel Sci. Technol. 55, 73 (2010).

64. P. Wagh, R. Kumar, R. Patel, I. Singh, S. Ingale, S.C. Gupta, D. Mahadik, and A.V. Rao, J. Chem. Biol. Phys. Sci. 5, 2350 (2015).

65. M.J. Al-Kheetan, M.M. Rahman, and D.A. Chamberlain, Constr. Build. Mater. 207, 122 (2019).

66. M.J. Al-Kheetan, M.M. Rahman, and D.A. Chamberlain, J. Mater. Civ. Eng. 31, 04019101 (2019).

67. M.J. Al-Kheetan, M.M. Rahman and D.A. Chamberlain, TRB 96th Annual Meeting, 17-02487 (2017).

Publisher's Note Springer Nature remains neutral with regard to jurisdictional claims in published maps and institutional affiliations. 